\title{
FOUCAULT E A POTÊNCIA NORMATIVA DO SABER NO CAMPO DA EDUCAÇÃO
}

\author{
FOUCAULT AND THE NORMATIVE POWER OF KNOWLEDGE \\ IN THE FIELD OF EDUCATION
}

CDD: 301.21

\author{
Alexandre Filordi de Carvalho ${ }^{1}$
}

\begin{abstract}
Resumo
A partir do pensamento de Foucault, o artigo tem por objetivo analisar as condições pelas quais o saber se constitui normativo para o campo da educação. Para tanto, serão desenvolvidas duas perspectivas. Na primeira, analisa-se a relação dupla do saber em sua potência de normação e de normalização. A seguir, apresenta-se a relação entre saber e homogeneidade, demonstrando algumas razões pelas quais é tão difícil mudar os regimes teóricos e empíricos no campo da educação. Com isto, pretende-se considerar, como hipótese de trabalho, que qualquer mudança ou transformação almejada para o campo da educação tem de passar pelo questionamento das (re)produções normativas.
\end{abstract}

Palavras-chave: Saber. Norma. Educação.

\begin{abstract}
Based on Foucault's line of thought, this article aims at analyzing the conditions through which the knowledge is constituted normative for the field of Education. To achieve this goal, two approaches will be developed. At first, it is going to be necessary to analyze the double relationship of knowledge in its normation and normalization. Then, it will be presented the relationship between knowledge and homogeneity, demonstrating some reasons why it is so difficult to change the theoretical and empirical practices in the field of Education. With this line of argument, I intend to consider, as a working hypothesis, that any change or transformation claimed to the field of Education must consider the questioning of normative (re)productions.
\end{abstract}

Keywords: Knowledge. Norm. Education.

\footnotetext{
${ }^{1}$ Professor no Departamento de Educação da Universidade Federal de São Paulo (UNIFESP). Doutor em Filosofia (USP) e em Educação (Unicamp). E-mail: afilordi@gmail.com - Guarulhos, São Paulo, Brasil.
} 


\section{INTRODUÇÃO}

$\mathrm{Na}$ época atual, todas essas instituições fábrica, escola, hospital psiquiátrico, prisão - têm por finalidade não excluir, mas, ao contrário, fixar os indivíduos. [...] A escola não exclui os indivíduos, mesmo fechando-os; ela os fixa a um aparelho de transmissão do saber. (FOUCAULT, 2001, p. 1482)

Eis a seguinte paródia como ponto de partida:

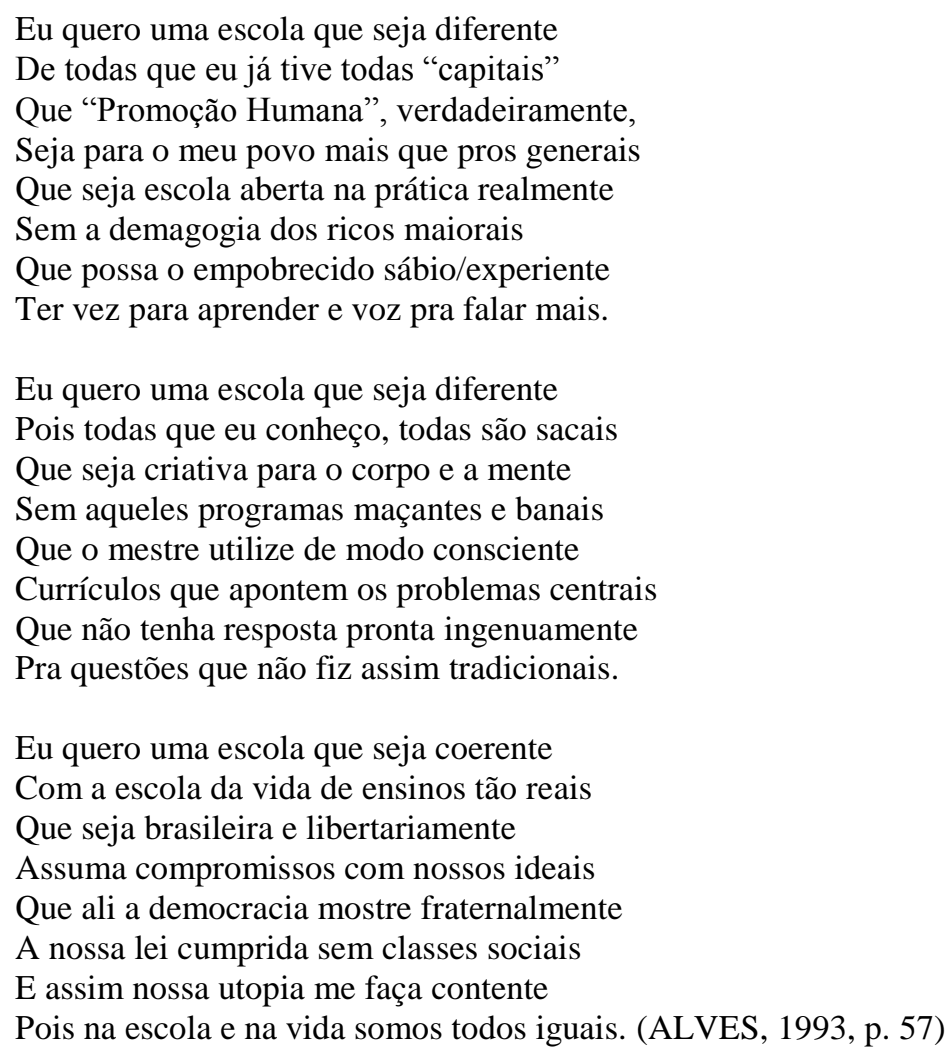

O bordão que se repete nos versos acima - "eu quero uma escola que seja diferente" - incide sobre uma temática constante: mudanças na escola, transformação das experiências educativas, educação crítica e emancipadora, a busca por uma educação diferente. Ao mesmo tempo, contudo, a expressão pode nos lembrar as angústias inevitáveis que, tal como no princípio de realidade psicanalítico, apontam para os limites reais entre as possibilidades factuais e as vontades irreais ou inexequíveis.

A posição do sujeito que deseja "uma escola diferente" ou "coerente" não é a de uma transparência soberana que faz mover, ou como se fosse capaz, a sua intenção com a 
possibilidade de execução do que deseja. Por mais que sejam nobres quaisquer tipos de intenção e de vontade movente que tenham por finalidade uma mudança na educação, alguns aspectos reais, isto é, um conjunto de estruturas discursivas e não discursivas, à revelia do sujeito que diz "eu quero", a ele se interpõem.

As ordens discursivas; as diferentes operações dos dispositivos de poder, de saber, de constituição de subjetividades; as estruturas arquitetônicas e as estruturas epistemológicas; os rituais disciplinares, arraigados nas repetições de padrões de comportamentos, de atitudes, de ações; a conjuração histórica de saberes que, mais ou menos, dimensionam as possibilidades de perspectivar o mundo, tanto em seu âmbito teórico quanto empírico; isto tudo que Foucault houve por bem denominar de o nosso a priori histórico não pode ser ignorado quando pensamos em um "eu quero", por mais nobre que seja, no âmbito da educação.

Pior ainda: este "eu quero" se situa, justamente, em certos condicionantes dos saberes que a ele são capazes também de possibilitar a sua consecução, isto é, a sua possível ou impossível realização. Neste caso, nada mais correto do que afirmar: querer não é poder.

O que buscarei desenvolver neste artigo é uma análise acerca das condições pelas quais o saber se configura como um referencial duplo para as possibilidades de experiências com a educação. Isto significa analisá-lo no âmbito de sua potência normativa. Saber e norma, em nossa sociedade ocidental, também são responsáveis pela composição operativa de nossas instituições sociais que, concomitantemente, refundam os saberes e as normas, num constante esforço de mais-valia normativa e normalizadora para constituir o sujeito normal, donde, mais uma vez, o saber e a norma serão retraçados.

É por isto que, para Foucault, todas as instituições - fábrica, escola, hospital, prisão têm por propósito fixar os indivíduos (FOUCAULT, 2001b). Esta fixação abrange os processos pelos quais os indivíduos são comparados, diferenciados, hierarquizados, homogeneizados, excluídos, partilhados entre o normal e o anormal. Numa ideia, o que estará em jogo é um estudo acerca da implicação que o campo da educação tem na (re)produção do que, como veremos, passou a ser esta nossa sociedade de normalização.

Para tanto, apresentaremos duas partes em que tais questões são desenvolvidas. A primeira parte denomina-se normação e normalização: efeitos da extensão social da norma. Nela, busco evidenciar a complexidade ativa da norma como efeito duplo na sociedade. De um lado, os saberes produzem valores normativos - critérios científicos, teóricos, legais e discursos capazes de gerar a figura do normal pelo valor da norma: normar; e, de outro lado, 
como se fosse um jogo de cara e coroa, o normar deduz o normal e, a partir de sua emersão, a norma gera processos de normalização: o anormal e o normal.

$\mathrm{Na}$ segunda parte, um problema surgirá em torno da seguinte perspectiva: saber e homogeneidade - porque é tão difícil mudar os regimes teóricos e empíricos no campo da educação. O intento é o de mostrar que os regimes de saberes não são excludentes do aparato normativo. Em termos singelos: a voz que diz: "eu quero uma escola que seja diferente" anuncia um tipo de saber subsumido em um jogo normativo e normalizante, mesmo que o sujeito do enunciado não tenha consciência disto.

O presente texto, entretanto, não busca dirimir as nossas angústias acerca da educação e de suas possibilidades de transformação. Apenas propõe considerar a necessidade de levarmos em consideração a extensão real da relação dos saberes no campo da educação com a norma. Assim, quem sabe, será possível pretender diagnosticar uma realidade que não podemos ignorar e que, malgrado qualquer paixão, utopia e vontade afirmativa, se interpõe entre nós e o campo da educação, como o nosso "aquário provisório", conforme Paul Veyne (2008) enfatiza, de onde podemos ainda circular e até mesmo tentar pensar e agir em busca de uma "escola diferente".

\section{NORMAÇÃO E NORMALIZAÇÃO: EFEITOS DA EXTENSÃO SOCIAL DA NORMA}

Como chegar a um bom termo para a norma? Se as possibilidades são tantas no entalhe de sua definição, não é por inconsistência ou articulação precária de sua formação conceitual, mas pela abrangência de seu domínio. Ou sob uma expressão original: devido à ampla e à singular inflação normativa implicada na própria norma ${ }^{2}$. Há, contudo, no contexto do curso de 1974-1975, denominado de Os anormais (2001a) e ministrado por Foucault no Collège de France, importantes referências à norma que são bem claras. Antes, porém, de chegar a elas, é fundamental manifestar aqui como acolherei tais proposições. Na minha ótica, a década de setenta marcará o pensamento de Foucault pela dupla e sináptica questão de como os indivíduos e os grupos são conduzidos no Ocidente. Quer dizer, trata-se de um constante

\footnotetext{
${ }^{2}$ A expressão é de François Ewald, e julgo enriquecedor trazer aqui a interpretação dele. Por ela, pode-se bem notar a norma como princípio de valoração a nos situar numa "singular inflação normativa que vai cortar uma multiplicidade de domínios técnicos e econômicos, como o conjunto das ciências morais, jurídicas e políticas que vão se refletir como ciências normativas". Desse modo, "a higiene, o urbanismo, a segurança, em matéria de poluição ou de energia nuclear, a qualidade dos produtos como a proteção dos consumidores, tudo isto procederia, indefinidamente, das decisões normativas" (EWALD, 1992, p. 202 e 203).
} 
diagnóstico das redes de construção de apoios, de formas, de mecanismos, de instituições e de saberes que se voltam para o controle, o cuidado, a otimização das forças produtivas, a disciplina - enfim, para o governo/condução que implica em submeter indivíduos e populações a certas condições e regras de comportamento e de atitudes. Concomitantemente, e mesmo para amadurecer tal enfoque, Foucault começa a sublinhar insistentemente a indissolubilidade do saber com o poder, como o curso de 1973-1974 demonstrou, à guisa de toda argumentação que toca $O$ poder psiquiátrico (2003). A medicina psiquiátrica, enquanto saber, tal como os demais saberes, estatui um tipo de saber cujo respaldo prático vai ao encontro de medidas comuns. Por isso mesmo, a definição de norma trará a lume a aplicação de um saber cujo estatuto científico incide completamente sobre as "condutas normais e anormais" (FOUCAULT, 2001b, p. 391).

Sendo assim, a norma se traduz como senha polivalente, cujo alcance se fia e se dispõe "como regra de conduta, como lei informal, como princípio de conformidade" (FOUCAULT, 2001b, p. 204). E, justamente por se tratar de regra, a sua razão de ser, sempre como referência que se institui de modo objetivado, confronta-se com "a irregularidade, a desordem, a esquisitice, a excentricidade, o desnivelamento, a discrepância" (FOUCAULT, 2001 b, p. 204. Seja qual for o seu aparato, a norma age e reage "como regularidade funcional, como princípio de funcionamento adaptado e ajustado" (FOUCAULT, 2001b, p. 204). É desta concepção, então, que submerge todo tipo de “"normal' a que se oporá o patológico, o mórbido, o desorganizado, a disfunção" (FOUCAULT, 2001b, p. 204) ${ }^{3}$.

\footnotetext{
${ }^{3}$ Embora o foco encontrado na obra de Georges Canguilhem, O normal e o patológico, seja totalmente distinto daquele trabalhado por Michel Foucault, acentuando "que não se ditam normas à vida", dada a inexistência de uma patologia objetiva, pois a "vida é essa atividade polarizada de conflito com o meio, e que se sente ou não normal, conforme se sinta ou não em posição normativa", donde o "homem normal é o homem na natureza", julgo que podemos encontrar algo que nos ajude a iluminar esta problemática da norma mesmo em Foucault (CANGUILHEM, 2006, p.174 e 234). Cerca de vinte anos após a publicação de $O$ normal e o patológico, Canguilhem elabora algumas Novas reflexões referentes ao normal e ao patológico. Em uma delas, intitulada "Do social ao vital", lemos algo de extrema importância: "quando se sabe que norma é a palavra latina que quer dizer esquadro e que normalis significa perpendicular, sabe-se praticamente tudo o que é preciso saber sobre o terreno de origem do sentido dos termos norma e normal, trazidos para uma grande variedade de outros campos. Uma norma, uma regra, é aquilo que serve para retificar, pôr de pé, endireitar. 'Normar', normalizar é impor uma exigência a uma existência, a um dado, cuja variedade e disparidade se apresentam, em relação à exigência, como um indeterminado hostil, mais ainda que estranho"(CANGUILHEM, 2006, p. 201). Ora, conforme PotteBonneville (2004), são as normas presentes nos tecidos sociais, inventadas e aplicadas com o intuito de impor uma exigência a uma existência, que fazem da norma uma peça mais do que fundamental para chegar à compreensão de que o sujeito na história ocidental é tramado sob as longas e contínuas linhas que multiplicam as regras aplicadas sobre ele. Poderíamos ainda dizer que as normas revivem a história dos limites de nossa cultura. História, por sua vez, que "traça um limite", "uma divisão original", como Foucault já colocava em 1961 no prefácio original à História da loucura.
} 
Com efeito, a norma permite a aplicação constante de um exame perpétuo, visando a um campo de regularidade, no interior do qual vai se avaliar sem cessar cada indivíduo, para saber se está conforme à regra, à norma que definiu a sua finalidade. Dada a sua capacidade de produzir uma finalização que foi trabalhada pelas aplicações rigorosas de controle e de disciplina, a norma também institui uma referência regular com o intuito de fazer conformar a essa referência um grupo de indivíduos qualquer. Assim, a compreensão signalética da finalização da norma, ou seja, os efeitos que ela obtém, será ou a normação (normation), no primeiro caso, ou a normalização (normalisation), no segundo, pois a norma está para a invenção e a aplicação tanto das técnicas quanto das tecnologias positivas de poder. E isso representa duas situações distintas, embora não totalmente estranhas uma a outra.

De um lado, normação se dá por meio de todos os processos disciplinares que, apoiados, interpenetrados, margeados pela norma - sem ignorarmos que toda "lei se refere a uma norma", que "a lei tem um papel e função de codificar a norma, de operar em relação à norma uma codificação" (FOUCAULT, 2004, p. 58) — forjam e alcançam para seus objetos o estatuto de normal. Assim, "a disciplina normaliza" por quatro motivos. Primeiro, porque ela "analisa, decompõe, decompõe os indivíduos, os lugares, os tempos, os gestos, os atos, as operações. Ela os decompõe em elementos que são suficientes para serem percebidos de um lado e modificados de outro" (FOUCAULT, 2004, p. 58). Segundo, “a disciplina classifica os elementos assim percebidos em função de objetivos determinados" (FOUCAULT, 2004, p. 58). Isso quer dizer que ela se instala por adestramento para obter os melhores gestos, as posturas, as atividades, a fim de empalmar os melhores resultados. Então, e por conseguinte, a "disciplina estabelece as seqüências ou as coordenadas melhores possíveis" a se fazerem sentir no "encadeamento de uns gestos com outros: como repartir os soldados para uma tarefa, como distribuir as crianças escolarizadas nas hierarquias e no interior de uma classificação" (FOUCAULT, 2004, p. 59), ou seja, como comparar, diferenciar, hierarquizar, homogeneizar, excluir. Finalmente, "a disciplina fixa os procedimentos de adestramento (dressage) progressivo e de controle permanente e, enfim, a partir daí, estabelece a divisão entre aqueles que serão considerados como inaptos, incapazes e os outros” (FOUCAULT, 2004, p. 59).

Em termos simples, sob os auspícios da norma, a disciplina faz a divisão operacional do normal e do anormal. Trata-se, portanto, mais de uma normação que de uma normalização, pois, neste caso, o "fundamental e primeiro na normalização disciplinar não é o normal e o anormal, mas a norma" (FOUCAULT, 2004, p. 59); ou seja, por ser o caráter da norma 
primitivamente descritivo por ser ela concebida assim, "a determinação e o reconhecimento do normal e do anormal se torna possível” (FOUCAULT, 2004, p. 59).

Ao contrário, de outro lado, se os processos de disciplina partem de uma norma e, relacionados às formas de adestramento efetuadas por ela, chegam a distinguir o normal do anormal, no caso da normalização, observamos exatamente o inverso. Situando o normal e o anormal a partir da ação da norma que reflete um tipo de identidade produzida, vem à tona um segmento sem continuidade e sem ruptura, portador de um coeficiente de distribuição e de organização que forma um tipo qualquer de população. Nada impede, de tal modo, sustentar que a população em Foucault representa "a curva normal” estatuída globalmente a incidir sobre os portadores das condições que se avizinham, que se enquadram nas mesmas estatísticas, sob as valorações aproximativas, no mínimo. Populações diferentes resultam das coabitações diferentes associadas às latitudes estranhas ou afins umas das outras. Aqui, em termos foucaultianos,

\footnotetext{
vamos ter uma marcação do normal e do anormal, vamos ter uma marcação das diferentes curvas de normalidade, e a operação de normalização consistirá em fazer jogar uns em relação aos outros estas diferentes distribuições de normalidade e a fazer de modo que os mais desfavoráveis sejam conduzidos àqueles que são os mais favoráveis. Temos então aqui algo que parte do normal e que se serve de certas distribuições consideradas como mais normais que as outras, mais favoráveis, em todo caso, que as outras (FOUCAULT, 2004, p. 65).
}

Os processos de normalização, portanto, partem do que se estabilizou como normal para se deduzir uma norma; quer dizer, um princípio ou prática por intermédio do qual a norma se fixa e desempenha um papel operatório, focalizado nas divisões dos indivíduos que figurarão no interior de uma dada população, de uma curva normal.

Por esta via, é possível apreender a força onicirculante da norma. Embora seja capaz de plasmar todo tipo de processos negativos, melhor dizer, excludentes, pois tanto o normal quanto o anormal se descolam um do outro, sob outra perspectiva, a norma se instaura também por um processo positivo que será todo aquele concernente à inclusão que ela é capaz de produzir. Sem demora, então, faz sentido pensar que, de fato, "tornamo-nos uma sociedade essencialmente articulada sobre a norma" (FOUCAULT, 1994, p.75).

De um lado, porque a norma "implica um sistema de vigilância, de controle. Uma visibilidade incessante, uma classificação permanente dos indivíduos, uma hierarquização, uma qualificação, o estabelecimento de limites, uma diagnosticabilidade" (FOUCAULT, 1994, p.75). Logo, para que este círculo se feche, "a norma torna-se o critério da divisão dos 
indivíduos" (FOUCAULT, 1994, p.75). Entrementes, de outro lado, porque os indivíduos são imantados sob círculos de normalidades, há uma norma que faz reproduzir esses mesmos círculos, à medida que denotam a conjugação dos que se situam nas mesmas condições. É a norma aplicada às populações distintas. Assim, Foucault argumentou que

\begin{abstract}
na época atual, todas essas instituições - fábrica, escola, hospital psiquiátrico, prisão - têm por finalidade não excluir, mas, ao contrário, fixar os indivíduos. A fábrica não exclui os indivíduos; liga-os a um aparelho de produção. A escola não exclui os indivíduos, mesmo fechando-os; ela os fixa a um aparelho de transmissão do saber. O hospital psiquiátrico não exclui os indivíduos; liga-os a um aparelho de correção, a um aparelho de normalização dos indivíduos. O mesmo acontece com a casa de correção ou com a prisão. Mesmo se os efeitos dessas instituições são a exclusão do indivíduo, elas têm como finalidade primeira fixar os indivíduos em um aparelho de normalização dos homens (2001a, p.1482).
\end{abstract}

Ora, o fundamental, aqui, a meu ver, é evidenciar que o papel da relação normadisciplina foi crucial para que se estabelecessem as estratégias e as táticas presentes nos mecanismos aplicados com o intuito de conduzir indivíduos e de formar grupos a partir dos coeficientes de homogeneização. De tal modo, o que deve ser sublinhado é a profusão do poder de normação e de normalização na extensão social da norma. Tanto é, que o próprio Foucault argumentou que "a disciplina não foi tão importante e tão valorizada a não ser a partir do momento onde se tentava gerir a população" (FOUCAULT, 2004, p. 110). E o significado disso, ainda a ser apreendido em seu alcance na sociedade contemporânea, faz-nos pensar não simplesmente em "gerir a massa coletiva dos fenômenos ou geri-los no nível de seus resultados globais; gerir a população significa geri-la igualmente em profundidade, gerila sutilmente e geri-la no detalhe" (FOUCAULT, 2004, p. 110).

Nesse caso, como veremos a seguir, importa pensar a relação entre a nervura da norma e a consolidação de um tipo de saber que se tornou o saber da instituição escolar. Enquanto aparelho disciplinar, a escola também é um aparelho de transmissão de saber. E seria impensável atingir um nível tão homogêneo de sua "população", que veio a ser conhecida por alunado, estudantes, educandos - crianças, jovens e adultos em formação -, sem a lógica estratégica de um saber igualmente normativo e normalizador. 


\section{SABER E HOMOGENEIDADE: PORQUE É TÃO DIFÍCIL MUDAR OS REGIMES TEÓRICOS E EMPÍRICOS NO CAMPO DA EDUCAÇÃO}

Suponho que qualquer tentativa de problematizar o campo da educação se condicione a uma operação bem precisa: algum reposicionamento face ao saber. Se atentarmos para o fato de que a educação se circunscreve às cadeias produtivas de saberes atinentes às ciências humanas, áreas de múltiplas configurações que buscam fundamentar e gerir a sua empiricidade, vemos a dificuldade que se instala nas finalidades que as próprias intenções educativas empreendem. No limite, cada registro de saber que respinga no campo da educação ou que seja nele referência maior de tais finalidades, disporá um jogo de verdade para o qual, forçosamente, a conjunção subjetiva em formação dos indivíduos estará em xeque ${ }^{4}$. Nesta dimensão, como veremos, os saberes são responsáveis por garantir uma ascensão normalizadora da função de educar.

Seja como for, no saber é possível encontrar pontos de sutura tão fortes a condicionar a estrutura do encaminhamento de relações de forças, pois, para Michel Foucault - e isto não é nenhuma novidade -, toda instância de saber funciona antes como instância de poder, cuja engrenagem também operará sob a dependência do saber. O saber não deixará de envolver o poder, os pontos de aplicação pelos quais, vis-à-vis, "as relações de poder dão lugar a um saber possível, e o saber reconduz e reforça efeitos de poder" (FOUCAULT, 1987, p. 31), o que deve ser sempre levado em consideração.

A julgar pelas peculiaridades da trajetória da história ocidental, o saber, em nossa atual sociedade, assume estratégias hiperbólicas em sua eficiência, chegando, mesmo, a regular todos os planos, os encadeamentos e as experiências das coisas, enquanto produção objetiva; e as relações e as práticas humanas, enquanto produção subjetiva. Nesse nível, o saber arma-se e apresenta-se na positividade da verdade científica, na positividade dos dispositivos e na positividade das ações, pois ele incita à verdade, a tudo que o poder acampa e às manifestações de conduta. No limite, faz-nos ver que toda produção histórica é regulada, pois tipos diferentes e determinados de saber estão aplicando as suas forças nessa produção.

\footnotetext{
4 Apenas um exemplo: podemos pensar no âmbito das implicações didáticas, das fundamentações de determinada teoria da educação e, até mesmo, de uma visada política educacional que a apropriação e a difusão do pensamento de Jean Piaget (1896-1980), pelo campo da educação, trouxeram para a educação brasileira. A saga do construtivismo testemunhou e continua a testemunhar esse embate e a determinar o que se faz com a formação dos sujeitos que são, pelo construtivismo, direta ou indiretamente, afetados.
} 
Há uma relevante passagem de As palavras e as coisas que introduz de maneira muito esclarecedora o âmbito do saber como operador dos mecanismos da progressão da verdade, portanto, em seus planos reguladores. Nela, Foucault situa algumas formas pelas quais o sujeito pode se tornar, numa dada época, objeto de conhecimento e, inversamente, como esse estatuto do objeto de conhecimento teve efeito sobre as teorias do sujeito enquanto ser que vive, fala e trabalha. Eis a passagem:

as ciências humanas não tratam a vida, o trabalho e a linguagem do homem na maior transparência em que se podem dar, mas naquela camada de condutas, de comportamentos, de atitudes, de gestos já feitos, de frases já pronunciadas ou escritas, em cujo interior eles foram dados antecipadamente, numa primeira vez, àqueles que agem, se conduzem, trocam, trabalham e falam (FOUCAULT, 1999, p. 490).

É possível enxergar, no texto de Foucault, por intermédio do exemplo das ciências humanas, o homem já como objeto dissolvido, pois é dependente da relatividade de perspectivas com as quais é tomado por objeto, no peso do saber como verdade reguladora. Melhor ainda, no peso do saber engendrado pelo poder inventivo, pois nenhum poder está ligado ao desconhecimento, "mas[...], ao contrário, só pode funcionar graças à formação de um saber" (FOUCAULT, 2001b, p. 64).

Os efeitos contidos nestes termos são tão evidentes quanto assustadores. Revelam o aspecto englobante das ciências humanas que, a partir de suas pretensões de abordagem e de entendimento acerca do homem, convocam todos os diversos tipos de saberes que, de antemão, atuam sobre o próprio homem de forma reguladora. Assim, a cada instante que se indaga pelas condições de saberes que referenciam o campo da educação, ao mesmo tempo, atingem-se as formas pelas quais as regularidades discursivas acabam se naturalizando no seu esteio epistemológico e em suas justificativas empíricas. Ainda mais por que essa atuação se dá, notadamente, no registro das condutas, aliás, no âmbito das empiricidades mais essenciais.

Nesse caso, note-se a armadilha, um tipo de saber foi necessário como engrenagem antecipada para fazer mover as condutas. Donde, então, é possível encontrar, desde o nível do saber em seu aspecto científico, ou melhor, em suas verdades científicas, as expressões de forças reguladoras a agir constantemente nas coletâneas discursivas que caracterizarão esta ou aquela ciência, enquanto esta mesma ordem científica redobrará, em ação já antecipada - pois teorizada -, as formas práticas capazes de suscitar e de formar o próprio tecido de suas experiências. No limite, ao pensar na relação saber e sujeito, encontraremos neste recorte a 
expressão de reposta mutabilidade, a indicar que não há forma terminal acabada para o sujeito, pois jamais deixará de ser alvo de reverberação das constantes aplicações do saber.

Sendo assim, é preciso dilatar para níveis mais corriqueiros e ordinários, para a porosidade mais extensiva das camadas de condutas, que extrapolam o que vem a ser o saber na educação, à medida que ela o refina e o pulveriza, em sua eficiência reguladora. Mais do que isso, chegar à órbita das "imensas possibilidades de discurso", "discursos da banalidade", como também das práticas com elas interligadas (das possibilidades de discurso), a fim de não ignorarmos o uso e a aplicação de "um certo saber do cotidiano, ao menos parte de sua origem, e com ele, uma grade de inteligibilidade que o Ocidente começou a colocar sobre nossos gestos, sobre nossas maneiras de ser e de fazer" (FOUCAULT, 1994b, p. 248), amalgamando desde o silêncio mais cálido "a mesquinharia tão vergonhosa de suas intenções" (FOUCAULT, 1994b, p. 244) ${ }^{5}$. Que, concebido desta forma, é inegável dizer, torna-se absolutamente impossível e insensato intentar atingir o saber em seu fundo. Recoberto e entrecruzado com a trama do cotidiano, ele se perde e se confunde com as infinitas histórias minúsculas a latejar em rotas desconhecidas da existência humana.

Tal perspectiva é de extrema valia. Ela desloca a possibilidade de pensar que as grandes implicações de uma capacidade reguladora, na educação, vêm à luz apenas por intermédio das destacadas fundamentações teóricas ou das celebradas discussões em torno de práxis. Toda e qualquer maneira gestual, da mais simples à mais banal forma cotidiana, até o refinamento mais ritualístico de um procedimento, condiz com a mesquinharia reguladora do saber. Em termos mais simples: não somos inocentes quando nos encontramos numa relação educacional qualquer. Da produção à reprodução de uma pedagogia cotidiana e amparada por um savoir-faire ingênuo, ou colado à determinada representação de papel social - o professor que aprendeu a fazer repetindo outros fazeres, mas sem saber por que o faz -; da pretensa lucidez mais arguta enraizada em uma teoria qualquer, é a engrenagem movente do saber que está em operação. Saber que faz dizer, que faz agir, que faz poder fazer, que faz poder saber.

\footnotetext{
5 Ter em mente, a este propósito, a interpretação de Deleuze, é não abrir mão de uma importante chave esclarecedora de análise do saber. Levando em conta que "o saber é um agenciamento prático, um dispositivo de enunciação e de visibilidade", então, poderia pôr em relevo que o saber, além de não ser a ciência, está orientado para toda e qualquer prática: "Apenas existem práticas, ou positividades, constitutivas do saber: práticas discursivas de enunciado, práticas não-discursivas de visibilidades” (DELEUZE, 1986, p. 58-59). Isso ajudará a buscar no saber os procedimentos estabelecidos por certas práticas cujos exercícios e domínios chancelam processos e procedimentos indissociáveis de certos agenciamentos de forças necessários para a formação do sujeito como função derivada dessas práticas.
} 
Não é sem sentido, então, que, ao tomar a ideia de grade de inteligibilidade do saber a partir de suas intenções, Foucault argumentou que é permitido ver emergir um saber que "não toma corpo somente em textos teóricos ou nos instrumentos de experiência, mas em todo um conjunto de práticas e de instituições" (FOUCAULT, 1994a, p. 844). Dessa maneira, a sua condição de existência depende do que ele designou de "maquinaria", isto é, de uma série de aparatos que "incita, suscita, produz; que faz agir e falar" (FOUCAULT, 1994b, p. 251). Há, outrossim, um processo de convergência do saber para si mesmo, dentro desta maquinaria. Uma vez que ele é inseparável dos procedimentos que o estabelecem, como se isso não bastasse, também é capaz de criar novos procedimentos para efetivar as suas aplicações. E será no âmbito dos processos de seu ordenamento, no alcance de sua homogeneização, condição sine qua non de toda regulamentação, acrescida de sua relação com a norma, que o saber atuará, desdobradamente, efetivando-se na direção da ordem das coisas, dos indivíduos e dos grupos humanos; enfim, conectando-se diretamente com as técnicas e as tecnologias aplicadas à condução de tudo e de todos, portanto, ao ponto fundamental da constituição dos sujeitos: o da disciplina.

$\mathrm{Na}$ realidade, o entendimento do saber permite antecipar a estrutura fundamental do poder disciplinar porque, aliás, ele não viria a ser, se não fosse imanente à formação, à organização e à circulação de um saber. Para ser mais preciso, de aparelhos de saber, quer dizer, de instrumentos efetivos a viabilizar a sua acumulação, "de técnicas de arquivação, conservação e registros, de métodos de investigação e pesquisa, de aparelhos de verificação" (REVEL, 2002, p. 56), enfim, uma série amplamente contundente capaz de dar-lhe visibilidade e circulação desde essas intervenções. Mas como o saber se tornou disciplinado a ponto de desdobrar a disciplina, a partir dele mesmo? Ou ainda, como o saber passou a infligir todo tipo de correção e de atuação disciplinar, assim, reativando o campo normativo?

Quando certos procedimentos intervieram a fim de organizar cada saber como "disciplina" do conhecimento, processou-se, nas dobras epistemológicas do século XVIII$\mathrm{XIX}$, às quais, concernente a isto, ainda somos herdeiros, um tipo de empreendimento que desenvolveu, junto a todo saber, novas regulamentações com o propósito distributivo de equivalências e de exclusões. É possível dizer que as formulações de problemas específicos advindos de um saber que se especializa como ciência, como domínio geral regulador de diferentes saberes, irão se desdobrar "no século do disciplinamento dos saberes" imbricado com os problemas de "homogeneização, normalização, classificação e centralização" 
(FOUCAULT, 2002, p. 216). E, nisto, já pouco importa o tipo de objeto que a ciência focaliza ou enquadra, sobretudo ao pensar em referências ou quadro teórico de compreensão; raramente ela se desvirtua da "organização de cada saber como disciplina", do "escalonamento desses saberes" e de sua "intercomunicação, sua distribuição, sua hierarquização recíproca numa espécie de campo global ou de disciplina global a que chamam precisamente a "ciência" (FOUCAULT, 2002, p. 217-218). E não seria, assim, toda concepção possível de um objeto chamado sujeito, passivo de um entendimento já tão disciplinado e arraigado nas regras que subsistem, explícita e implicitamente, em qualquer forma de saber? A dependência de sua enunciação, a priori, já indicaria isto. Há mais, contudo.

Para processar o saber dessa maneira, seria interessante ter em mente o eixo prática discursiva/enfrentamento de poder, por onde Foucault concebeu "um imenso e múltiplo combate dos saberes uns contra os outros — dos saberes que se opõem entre si por sua morfologia própria, por seus detentores inimigos uns dos outros e por seus efeitos de poder intrínsecos" (FOUCAULT, 2002, p. 214). São, no mínimo, curiosos, embora as consequências sejam mais amplas, os resultados advindos dessa forma de combate. Além dos enfrentamentos inevitáveis ao redor das disputas pela fixação dos discursos, a fim de lograr a melhor chave de entendimento acerca das positividades e das coisas entrelaçadas a elas, a dependência inconteste do sujeito como fragmento consequente de um saber dispensado à sua visibilidade, concomitantemente, vai lhe negar a luminosidade extraviante, quando não é encontrada em nenhum tipo de saber. As forças que agem sobre ele, desse ponto de vista, são as forças que permitirão, inicialmente, seus modos de ser. Incontornável "destino" ao qual o saber está sujeito e o qual pouco pode controlar.

Não sem sentido, além disso tudo, Michel Foucault localizou, muito bem, quatro procedimentos responsáveis por movimentar a fortuna dessa morfologia do saber, cujas conexões articular-se-ão como delineadores de sua instância disciplinadora, todas elas ligadas à extensão social da norma: processos de seleção de saberes, normalização, classificação e homogeneização.

Nos processos de seleção de saberes, foi necessário que houvesse ou que se processasse um tipo de "eliminação, a desqualificação daquilo que se poderia chamar de pequenos saberes inúteis e irredutíveis", até mesmo, "economicamente dispendiosos" (FOUCAULT, 2002, p. 215). Em jogo, a emersão de linhas delimitadoras, portanto 
constritoras, responsáveis pela elaboração de uma espécie de seleção de saberes cuja homogeneização a se firmar estaria sempre em consonância com a estabilidade capaz de produzir, ou seja, de fornecer um estatuto reconhecido acerca do que se pretende. É assim que o louco não está mais preso à sua loucura, mas ao saber que produz a sua loucura; o preso não estará limitado às grades, mas ao Direito-Medicina legal que passa a atribuir e a determinar a sua periculosidade; o doente não mais fadado ao destino de sua doença, mas a toda sorte de manipulação de um saber que a clínica dispensa à sua doença; o sujeito não mais detido em sua subjetividade inefável, mas nos limites dos saberes que estabeleceram todas as suas finitudes - enfim, os terrenos de suas ações sob alguns campos de experiências.

Na mesma proporção, é assim que o campo da educação, inevitavelmente relacionada à história de suas empiricidades, alojará na escola toda forma de saber possível, como condição normativa para se educar, e desqualificará outros tipos de saberes. As constantes reformas empreendidas neste amplo domínio, das políticas às pedagógicas, testemunham a dinâmica reguladora do saber que avaliza como caduca uma prática e a outra como inovadora, desqualificando aquela e enaltecendo esta. Educar torna-se, com efeito, um ato condicionado às seleções de sabres que chancelarão o seu ato, ao mesmo tempo, como adequado e pertinente, ou como inadequado, ultrapassado e errôneo.

Em decorrência desse estatuto, em segundo lugar, vê-se cristalizar o veio da normalização do saber. É dizer, normalização dos saberes dispersos, permitindo "ajustá-los uns aos outros, fazê-los comunicar-se entre si, derrubar as barreiras do segredo e das delimitações geográficas e técnicas, em resumo, tornar intercambiáveis não só os saberes, mas também aqueles que os detêm" (FOUCAULT, 2002, p. 215). Expressão mais contundente da homogeneização, a normalização do saber eleva à última potência a capacidade de certas áreas do conhecimento científico penetrarem ubiquamente em todos os níveis da existência, como vai se processar com "a medicalização geral do comportamento, das condutas, dos discursos, dos desejos, etc.” (FOUCAULT, 2002, p.46) ${ }^{6}$. Não sem, contudo, se valer do par siamês de

\footnotetext{
${ }^{6}$ A este propósito, se lembrarmos de como Foucault prezava os acontecimentos no prisma da atualidade, sobretudo concernente a uma visão crítica que não se conforma ao atual, mas que distende nele outras forças a fim de provocar novas experiências, ficaríamos ainda mais sensibilizados pelo diagnóstico preciso, elaborado por François Ewald (1997), referente à atualidade dos processos de medicalização nos quais estamos, independentemente de nossa vontade, envolvidos. Assim argumenta Ewald: "É preciso constatar que, hoje, a medicalização nunca foi tão forte e nem incitante. O que significa dizer que é no seio do exercício da medicina que hoje se encontra os lances de poder mais graves, mais fundamentais. E a medicina que desponta, a medicina genética, é uma medicina cujo anúncio é um império terrível. Temível porque é uma medicina que tem uma característica previsível: a partir de agora tem-se a possibilidade, ao menos potencialmente, de saber para cada um de nós, antes mesmo de nascermos, nossas predisposições à doenças que teremos" (EWALD, 1997, p. 210).
} 
toda disciplina, que é a vigilância desses mesmos comportamentos, condutas, discursos, desejos, enfim.

A medicina, assim, é o exemplo mais acabado da normalização do saber em seu nível de aplicação. Por ele, os cenários da seleção, da qualificação, da utilização da vida e da morte, do controle, do policiamento dos instintos e dos prazeres - enfim, dos enquadramentos quantitativos e qualitativos do que será prejudicial ou não à vida passarão a atuar como força de sujeição; como força difusora, a exigir a correta justificativa a tudo que se faz. O sujeito, assim, também vai se constituindo como espectro deformado da ação desse saber normalizado.

Mas é claro que, se há um lugar onde saberes se intercambiam para buscar equivalências estratégicas de consolidação de certas práticas, esse lugar é o campo da educação. Psicologia, sociologia, antropologia, história, filosofia, linguística, para nos valermos de apenas alguns exemplos, tecem e retecem, como as fiandeiras do Destino, os ajustes necessários que projetam certo ponto de vista cego, concernente ao entendimento, do que venha a ser educar, a educação, certa experiência educativa, etc. Pior ainda, é a associação das funções "psi” e a sua recorrência na educação - psicopedagogia, psicologia da educação, psiquiatria - que, na atualidade, revigoram com força institucional e discurso de autoridade o conclame empírico de observação e de atenção ao anormal. O mesmo empreendimento, é claro, faz ressaltar o seu outro, isto é, conclama à ordem o normal como referência anteposta ao anormal: escola como lugar de produção de comparações, de hierarquizações, de emparelhamento das distinções meritocráticas - alunos bons, ruins, inteligentes, atrasados, bem comportados, arredios - a lista se estende.

Com efeito, do garotinho deficitário, problemático, indisciplinado, ao superdotado, é da medicalização da educação que nos avizinhamos e, a partir dela que se outorgam as justificativas mais intervencionistas nas famílias, nas crianças, nas práticas pedagógicas. Lugar cego de onde quem fala pode ser um médico que não sabe educar e de um educador que não sabe medicar: mas ambos se entendem muito bem, pois, malgrado as diferenças das ordens discursivas, é um saber normativo que está em jogo e em operação.

Incrível notar, a julgar por estes termos, como se delineia uma possibilidade de sujeição in vitro não a um saber, mas ao mapeamento de experiência que não mais fugiria ao nosso espanto, ao desconhecido - experiência determinante, experiência apreendida a priori. A vida a ser concebida, de antemão, passa a ser selada à guisa de um saber controlador de suas reais potencialidades. 
Entretanto, ainda há mais. Em terceiro lugar, com o intuito de canalizar com eficácia o aspecto normalizador do saber, ou seja, de otimizar a sua aplicação, uma classificação hierárquica será acionada. Doravante, como argumentou Foucault (2002, p. 215-216), é permitido, de certo modo, encaixar os múltiplos saberes "uns nos outros, desde os mais específicos e mais materiais, que serão ao mesmo tempo os saberes subordinados, até as formas mais gerais, até os saberes mais formais, que serão a um só tempo as formas envolventes e diretrizes do saber". Com efeito, na ordem dos saberes, de onde se fala, como se fala e a sua finalidade, evidenciarão a rede hierárquica na qual todos estamos implicados. Além disso, é claro, em jogo encontra-se o que é permitido fazer, sob a chancela de um saber que difunde as suas regras homogêneas em seus espaços acolhedores, quer dizer, o saber se aplicará em todos os níveis de condutas hierarquizando, assim, tanto o agente quanto a ação.

Quem pode falar, onde, quando, quanto e sobre o que compõe o consenso normativo mais aceitável no âmbito da educação. E, para esta possibilidade não correr o risco de perder a força de seus efeitos numa eventual falta de referência ou de diretriz, ao mesmo tempo hierárquica, uma outra operação se processará com o intuito de permitir o "controle desses saberes". Trata-se da irradiação centralizada dos saberes. A centralização "assegura as seleções e permite transmitir a um só tempo de baixo para cima os conteúdos desses saberes, e de cima para baixo as direções de conjunto e as organizações gerais que se quer fazer prevalecer" (FOUCAULT, 2002, p. 216). Mas algo, nisso tudo, não está claro: quem ou o que é o responsável por todas estas operações realizadas a fim de disciplinar o saber?

A notar pelos termos postos na explicação da centralização do saber, sobretudo por sua relação com as organizações gerais que o fazem prevalecer, não se trata de buscar a nascente determinante dessas disposições; a sua origem transparente. Mesmo que as relações de controle impostas pelo Estado Moderno a partir do século XVIII sejam fundamentais, como o próprio Foucault explicou no contexto destas questões, sou da opinião de que, sob o manto do dispositivo, da implicação permanente entre saber-poder e das relações de forças, estas operações são como processos de racionalização do saber. São as interações que contam para a sua eficácia. Impossível não dizer, assim, que "os níveis, cortes, estratos, ao mesmo tempo quantitativos e qualitativos, entre os diferentes saberes" se tocam numa forma de "saberes múltiplos, independentes, heterogêneos e secretos, e não no progresso constante do dia sobre a noite" (FOUCAULT, 2002, p. 215). Que haja certa astúcia do saber aí me parece 
evidente, pois, no fundo, mesmo o excluído pelo jogo da homogeneização o foi para trazer à tona uma forma correlata à exclusão: por exemplo, o desqualificado.

Podemos ver que as engrenagens responsáveis por essas operações são mediações históricas que não escapam ao microacontecimento. O triste destino nosso, no Ocidente, é o de depararmos em qualquer canto com qualquer tipo de saber agente de uma construção de inteligibilidade, arraigado, desde a sua constituição, nesta trama tão complexa e apertada que perpassa o saber da ciência, do Estado, das práticas, ao saber ignorado; enfim, todo saber pautado numa relação de força que normatiza e normaliza. Saber que compele a um umbral de passagem, de situação, de condições para o vir a ser, contanto que a sua fundação mesma não escape às suas regras.

\section{CONSIDERAÇÕES FINAIS: ENTÃO O SABER ENGESSA O CAMPO DA EDUCAÇÃO?}

Em que pesem tais termos, na prática, é possível ver, em dois níveis, o que acarreta todo esse contexto geral. Em um primeiro nível, torna-se inegável que a própria maneira pela qual o saber foi estruturado no Ocidente revela os aspectos de suas aplicações como estratégias cujos propósitos vão ao encontro de um "mundo do regulamento indefinido, do regulamento permanente, do regulamento perpetuamente renovado, do regulamento cada vez mais detalhado" (FOUCAULT, 2004, p. 348). O refinamento e a progressão dessa vitalidade regulamentar não se explicam somente pela disposição de um saber que se orienta numa direção concreta, porém, ainda mais por qualquer princípio, regra, lei ou discurso cujos funcionamentos móveis, permanentes, parciais ou detalhados são voltados para uma realização qualquer.

Em um segundo nível, o saber disparará um tipo de agenciamento tão eficaz que será capaz de criar condições para um ordenamento tão profundo e permanente do tempo, das atividades, dos gestos e das aplicações distintas dos saberes. A regulamentação, assim, nos colocará no mundo da ordem; de "uma ordem pela qual os corpos não são senão superfícies a atravessar e volumes a trabalhar, uma ordem que é como uma grande nervura de prescrições, de sorte que os corpos sejam assim parasitados e perpassados pela ordem" (FOUCAULT, 2003, p. 04). É desse prisma, aliás, que confluirão as técnicas e as tecnologias políticas como instrumentos de toda ordem sob a qual a matéria potencial a ser trabalhada em favor de uma subjetividade, os corpos individuais e os coletivos sofrerão as efetivações determinantes de 
forças. Tanto é assim que "a norma é o que pode tanto se aplicar a um corpo que se quer disciplinar quanto a uma população que se quer regulamentar" (FOUCAULT, 2002, p. 302).

Levando isso a bom termo, podemos pensar o quão evidente toda relação entre teoria e prática se torna miscível. Ambas dizem respeito e expressam o mesmo umbral por onde as “palavras e as coisas" passam e tornam a ser o que são. Nada mais ingênuo, portanto, pensar que afetar uma perspectiva não seja afetar a outra. Não é à toa que paira sobre nós uma séria dificuldade nas necessidades, quais sejam elas, de alterar, de rever, de transformar ou de propor algo novo no campo da educação. Tanto os saberes que compõem toda série de saber sobre a educação, como a própria educação, deveriam ser questionados na fundamentação epistemológica de suas normações e de seus efeitos normalizantes. O mesmo com relação às práticas que tais saberes refundam e justificam.

A julgar que se coaduna com o saber um sistema de nervura de prescrições, seguindo o pensamento de Michel Foucault, poderíamos dizer, imantados pela força da mesma metáfora, que a norma seria a parte central, a própria medula espinhal de onde se irradiam as relações produtivas do saber-poder, das mais evidentes até as mais capilares formas de vínculos prescricionais. Sem dúvida, regulamentação, ordem e disciplina são costuradas pelo idêntico alinhavo. Então, deve estar claro, nesse sentido, que a norma se exerce em relação aos domínios a que se aplica. Mas para essa empreitada subjaz toda série de exigências e, até mesmo, coerções, que, respaldadas pela situação disciplinadora do saber, de antemão, projetam a norma para a congruência do poder; melhor dizer, de ações produtivas, pois se tratará de ações qualificadoras, restritivas, incitantes, disciplinares, veridiccionais, corretivas enfim, ações que dão azo ao uso e à aplicação de uma força con(formadora).

Essa perspectiva, sem dúvida alguma, invoca outra vez a dimensão política na qual estamos envoltos, pois a norma, por conseguinte, “não é simplesmente um princípio, não é nem mesmo um princípio de inteligibilidade; é um elemento a partir do qual certo exercício do poder se acha fundado e legitimado" (FOUCAULT, 2001a, p. 62). Nem seria preciso fazer notar o grau de comprometimento que qualquer política educacional tem com essa perspectiva. Nesse caso, o que está em questão é o estatuto original do saber como a instância responsável por engendrar um tipo de poder que se legitima por intermédio da aplicação do próprio saber. Como o saber é o canal livre para o tráfego da norma, e vice-versa, ali ela não apenas encontra a sua fundação como se legitima, à medida que o saber se aplica, ou seja, opera um jogo de forças. 
Para bom entendedor, pingo é letra. Se há um movimento necessário que se volta para afirmação de uma busca, tal como aquela do enunciado da paródia - "eu quero uma escola que seja diferente", não nos iludamos, o seu começo deve estar no questionamento das próprias normas instauradas e reproduzidas no campo da educação. Não são as discussões pautadas apenas nas mudanças dos grandes quadros teóricos ou empíricos que devem estar em jogo. As minúcias da norma é que devem ser revistas com grande vigor. A substituição de um saber por outro é uma reprodução inesgotável de um campo normativo, isto é importante de não ser esquecido.

Refundar a nossa relação com a pequena nervura normativa no campo da educação implica ações mais cuidadosas face às repetições cotidianas que ecoam os nossos preconceitos; que reproduzem a nossa ação mecânica, a aceitação muda dos procedimentos de microexclusão; que inauguram o tempo todo a politização dos espaços hierarquizados ou homogeneizados; que dão sentido às ações mais descabidas em nome de um saber que tem de vencer: teoria benfazeja que tudo explica, que tudo aponta e que tudo denuncia; ações que calam outras ações pela desqualificação, pelo jogo perverso do vexame, pelo uso espetacular da ironia e do isolamento; saber que refina todo tipo de sabor normativo.

Seja como for, o campo da educação é este terreno movediço a ser cuidado, desde a grande ordem dos saberes que o fundam como saber, até a nervura menor de toda série normativa. Afirmar isto, contudo, não é redizer uma norma, mas buscar um indício de conjuntura para que algo se produza em nosso pensamento, pois, de qualquer modo, "onde há humanos só os humanos resolvem" (BRECHT, 2009, p. 189).

\section{REFERÊNCIAS}

ALVES, Carlos Alberto Rodrigues. Poder crer, é incrível. Curitiba: Assintec; CEBEP; CELADEC, 1993.

BRECHT, Bertolt. A santa Joana dos matadouros. São Paulo, SP: Cosacnaify, 2009.

CANGUILHEM, Georges. O normal e o patológico. 6. ed. rev. Rio de Janeiro, RJ: Forense Universitária, 2006.

DELEUZE, Gilles. Foucault. Paris: Éditions de Minuit, 1986. 
EWALD, François. Foucault et l'actualité. In: FRANCHE, Dominique. et al (Org.). Au risque de Foucault. Paris: Éditions du Centre Pompidou, 1997. p.203-212.

Michel Foucault et la norme. In: GIARD, Luce. (Org). Michel Foucault: lire

l'oeuvre. Grenoble: Jérôme Millon, 1992. p. 201-221.

FOUCAULT, Michel. As palavras e as coisas. São Paulo, SP: Martins Fontes, 1999.

Dits et Écrits I - 1954-1969. Paris: Gallimard/Seuil, 1994a.

Dits et Écrits I - 1954-1975. Paris: Gallimard, 2001a.

Dits et Écrits III - 1976-1979. Paris: Gallimard/Seuil, 1994b.

Em defesa da sociedade. São Paulo, SP: Martins Fontes, 2002.

Le pouvoir psychiatrique: cours au Collège de France (1973-1974). Paris:

Gallimard/Seuil, 2003.

Os anormais. São Paulo, SP: Martins Fontes, 2001b.

Sécurité, territoire, population: cours au Collège de France (1977-1978). Paris:

Gallimard; Seuil, 2004.

Vigiar e punir. Petrópolis: Vozes, 1987.

POTTE-BONNEVILLE, Merleau. Michel Foucault, l'inquiétude de l'histoire. Paris: PUF, 2004.

REVEL, Judith. Le vocabulaire de Foucault. Paris: Ellipses, 2002.

VEYNE, Paul. Foucault: sa pensée, sa personne. Paris: Albin Michel, 2008. 